\title{
BENEFITS OF ARTIFICIAL INTELLIGENCE AND MACHINE LEARNING IN MARKETING
}

\author{
Kristina Kaličanin*, \\ Milica Čolović, \\ Angelina Njeguš, \\ Vladimir Mitić
}

Singidunum University, Belgrade, Serbia

\begin{abstract}
:
Artificial intelligence (AI) impacts numerous aspects of life in the form of smart devices and smart applications, designed to understand consumer behaviour, needs, and preferences in order to deliver customized experiences. AI has been one of the primary drivers of innovation in marketing. Marketers are already leveraging the advantages of AI to gain valuable insights into customers, competitors and markets. Besides, AI automate tasks, reduce costs, and improve workflows. This paper examines the current and potential applications of AI within marketing by providing comprehensive overview of existing academic research.
\end{abstract}

Keywords:

machine learning, marketing intelligence, smart application.

\section{INTRODUCTION}

Artificial intelligence (AI) is an essential tool for marketers. Especially in the era of big data, where the different format of a large volume of data are generated every second, without AI it would be impossible to get an insight of valuable data in real time. On the other side, customers have high expectations for a more personalized experience. Therefore, to get closer to the customer, and deliver the right message at the right time, marketers need to implement some AI application (e.g. chatbots, personal assistant, smart application).

What really makes marketing successful today is application of machine learning (ML) algorithms. ML represents the main pillar of artificial intelligence that consists of diverse mathematical models (e.g. statistics, probabilistic, neural networks). These models are applied on large datasets in order to identify patterns in data, to learn or to predict output values. Lately, with deep learning (DL) algorithms, computer's ability to learn and acquire new knowledge has become reality.
Correspondence:

Kristina Kaličanin

e-mail:

kkalicanin@singidunum.ac.rs 


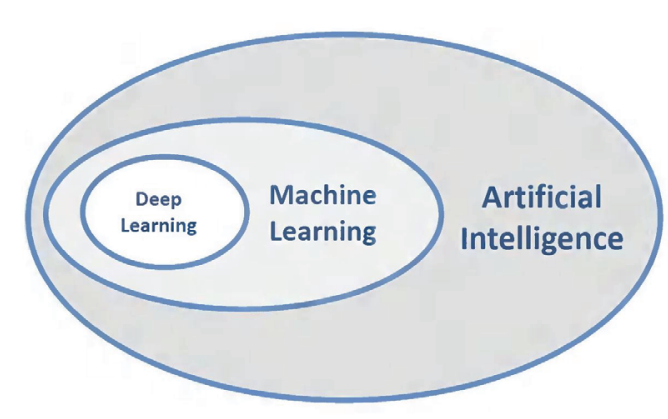

Fig. 1. The position of ML and DL in artificial intelligence

The most popular AI applications in marketing are: content creation, voice search, predictiveness analysis, lead scoring, ad targeting, and dynamic pricing. With these AI applications, marketers can analyse customers based on their movement and behaviour over time in order to achieve dynamic micro segmentation and forecast their future movements, in general. With all these specific information marketers can focus on the specific needs and create a long-term relationship with the brand. Micro-segmentation is helping brands to communicate in personal with each costumer and to improve loyalty and life time value. [1]

Brands are using the power of the AI for personalisation of email/SMS marketing campaigns, which provides better connection, and transformation of this users into clients. Digital advertising is the area with the most successfully adopted AI. Facebook and Google are good examples of AI and machine learning usage. They analyse the user's information, their interests, demographic in order to learn and detect the best audience for their brand. Predictive analysis is the usage of data, statistical algorithms and machine learning techniques with the goal to identify all the future conclusions based just on data history. Besides, AI can lower production costs, increase competitiveness and profit. [2] Therefore, AI does not exist to replace the jobs of marketers, neither advertisers but to help them to develop their creative and strategic potential. In addition they should learn to use advantages of AI.

In this paper the comprehensive analysis of $\mathrm{AI}$ and ML application in marketing is given. The paper is organized as follows. Section 1 introduces the basic concepts of AI and ML. Section 2 briefly represents literature review. Section 3 describes some of AI applications in marketing. Finally section 4 presents the conclusions.

\section{MACHINE LEARNING ALGORITHMS AND THEIR APPLICATIONS IN MARKETING}

\section{Artificial intelligence and Machine Learning}

The field of AI really came into existence with the birth of computers around the 1940s and 1950s. For the earlier period of its development, attention was clearly focused on getting computers to do things. [3] In period of 1960s and 1970s there was a real philosophical discussion about how close human brain and computer could be. Next decade from 1980s to 1990s brought a whole new approach. Artificial computer brains had opened up possibilities and created a completely new set of questions.

Next decade has brought advanced software intelligent agents. An intelligent agent is a software with a possibility to assist people and to act on their behalf. Agents can automate repetitive tasks, remember things that user forgot, learn from the user or can make recommendations. [4] AI could be intelligent in its own way now: there is a potential to be bigger, faster and better. People realized that artificial brain could outplay human brain. AI technologies are used in numerous internet tools: search algorithms, recommendation system and systems for creating web sites. [5]

The AI is unsurpassed by human brain nowadays. AI applications in the finance, military and manufacturing sectors are something that human brain cannot compete with. Artificial brains now have their own bodies. Three capabilities of AI are: to sense, comprehend and act. They are supported by the ability of the AI to learn from experiences and adapt over time. First capability includes images, sounds and speech. Facial recognition is the latest practical proof of improving productivity. Natural language and inference engines make better comprehension of collected information. AI systems can take different actions through technologies in physical world. Auto-pilot in cars is the best example. [6]

There are two types of AI: Strong and Weak AI. Strong AI can be also called artificial general intelligence. It includes all the machines with consciousness, mind and sense, and they are applied not in only one specific area. Weak AI, also known as artificial narrow intelligence, has focus on a very specific task (self-driving car). Behind AI, machine learning or more specific deep learning are algorithms with the aim to imitate the structure and function of the human brain. [7] 
Artificial intelligence relies on machine learning (ML) algorithms that are applied on large datasets in order to identify patterns in data, to learn or to predict output values. According to Samuel (1959), ML is computer's ability to learn without specifying a set of program instructions. [8] Lately, with deep learning (DL), which are artificial neural networks algorithms, computer's ability to learn and acquire new knowledge has become reality. Relationship among these fields are shown in Fig. 1.

There are several types of ML such as supervised, semi-supervised, unsupervised and reinforcement. In supervised learning, smart applications are taught by example. It means that dataset consists of inputs and desired outputs. Some supervised learning models are classification, regression, forecasting. For example, emails can be classified as spam or not spam, and classification algorithm should look at existing observational data and filter the email accordingly.

In unsupervised learning, since there is no a target value, algorithm analyze data i.e. focuses on their relations, structures, and interconnections. Some unsupervised learning models are clustering, and association. An association model is often used for market basket analysis in order to identify relationships between the products or services that people buy, and according to that to understand and predict their future behaviour.

\section{Marketing intelligence}

AI is reshaping marketing today. Marketing Intelligence includes all kinds of information that companies collect about a specific market in which they want to enter. Companies collect and analyse external data before entering and investing in this area. The information can be about population age or about their spending habits. Marketing intelligence is there to help to break down the data into smaller subsets before the relevant company department gets them. Each department needs different information. There are four the most important parts of marketing intelligence. [9]

- Competitor intelligence;

- Product intelligence;

- Market understanding;

- Customer understanding.

Together with a Machine Learning it can help us to predict all the customers' digital actions, to target the right customers with the best content just across the perfect channel, and all this at right time.

\section{Neuromarketing}

Neuromarketing (NM) refers to designing the content to elicit particular neurological reactions that are associated with buying or emotions linked to buying. NM studies the brain (neural networks) responses to advertising and branding (e.g. emotion recognition), and the adjustment of those messages. Technologies, such as functional magnetic resonance imaging (fMRI) and electroencephalography (EEG) measures specific types of brain activity in response to advertising messages. With neuromarketing companies learn why consumers make decisions, and what parts of the brain are motivating them to do so. Recently, NM is getting more attention of scholars in different settings. [10]

\section{LITERATURE REVIEW}

Choudhury \& Nur (2019) [11] have implemented several ML algorithms, such as logistic regression, decision tree, support vector, random forest, and multilayer perceptron classifiers in order to analyse customer's purchase behaviour for a retail superstore. They used dataset of 9259 customer sales data over the three months. To analyze customer purchase behaviour, they explored the quantity of each item that customer has bought. The results show that with multilayer perceptron $99.41 \%$ of accuracy has been achieved.

Lagree et al (2019) [12] have introduced a novel algorithm, titled GT-UCB that relies on probabilistic upper confidence bounds on the expected number of nodes, in order to find influential users in a graph. The goal is to maximize the spread of information on social media as part of the online marketing strategy. This type of online marketing is called influencer marketing, in which the sub-population of influential people is targeted instead of the entire base of potential customers. With proposed algorithm they showed that it leads to high-quality spreads.

A. Ajuri et al, (2018) [13] have shown how ML can help organizations to have more customers in their loyalty program. They described how discounts can make an influence on customers' decisions. They also think that managers should be involved in creating these programs because more loyal consumers will bring bigger revenue. Hospitality organizations should make loyalty programs with brands or with partners just because their costumers' experience will be improved and it will lead to increased loyalty. 
S. Dimitreska et al (2018) [14] have explained in which way $\mathrm{AI}$ is reshaping marketing in an era when machines really understand all the problems and can find solutions, just like people do. Technologies have an impact on companies in a way of making better, more competitive and productive business. Their conclusion is that future will bring even higher expectations from customers and that AI will help marketers to understand personalized customers' needs and wishes. Thanks to AI companies will be able to modify all customers' needs and new campaigns in real time.

Syam \& Sharma (2018) [15] have made a research of the fourth industrial revolution and its impact on personal selling and also on selling management. Their research was based on all seven steps which make the selling process. Their conclusion is that digitalization will have the biggest influence on selling process because it will be easier to understand consumers' behaviour and to make offers customized. They suggest to salespeople to use the advantage of ML and AI to study all the activities of the buying process in order to have more satisfied customers.

Olson \& Levy (2018) [16] have tried to show deeper relationship between customers and marketers and to improve that they can build a lifetime value models. Their research shows some of the most attractive applications that people use and their impact on every day activities. Microsoft has the biggest influence and it helps marketers and doctors, also biochemists, in their work by analysing a lot of data with very useful patterns.

Al-Sukkar et al, (2013) [17] have revealed what can make an effect on the process of applying AI in shaping marketing strategies. Their conclusion is a list of recommendations: first one is a practice of developed technological programs which are based on AI. They also saw the effects of applying AI on shaping different strategies and what is their impact: cost leadership strategy - to reduce costs but to keep a quality; differentiation strategies - to attend providing the highest quality of all the products in the market; alliance strategy - joining alliances with suppliers and agents with the goal of making efficient marketing activities; diversification strategy supplying market with different and multiple products; direct marketing strategy - it will increase the a possibility to get data basis about customers.

Nordlander, T. E., (2001) [18] have tried to improve that AI has already penetrated the business market. And the result of his research was positive, he found out that Microsoft Office packages have the best influence in working process. The main problem was the price for different and more useful programs for tracking production and the whole working process of big companies.

Stalidis, G. et al, (2015) [19] have presented how advanced data analysis, knowledge representation and neural networks technologies make together an intelligent information system for tourist destination marketing. After they added a new developed system based on Neural Network technology, they concluded that this new system could work out. Their efforts to classify unknown testing patterns were correct and they could manage it with acceptable accuracy.

\section{AI APPLICATIONS IN MARKETING}

There are numerous AI applications. One of the most popular is a chatbot. [20] A chatbot is an AI software which can help to simulate conversations through chats with the users. It uses natural language through websites, mobile applications, messaging applications or just through the telephone. It is shown in Fig. 2. It is described as one of the most advanced interaction between humans and machines. It is based on returning responses on questions that users have asked. It analyses all the users' requests and after that it is trying to identify the users' intent. When the intent is identified it must provide the most appropriate response. In this way companies get new opportunities to improve the efficiency and to reduce typical costs that costumer services bring.

Chatbot is programmed to work independently and it can give the answer in natural language with a response the same as the human. Responses are combination of scripts and machine learning applications. It has a huge database. Sometimes happens that the answer cannot be found and then a chatbot just deflect the conversation.

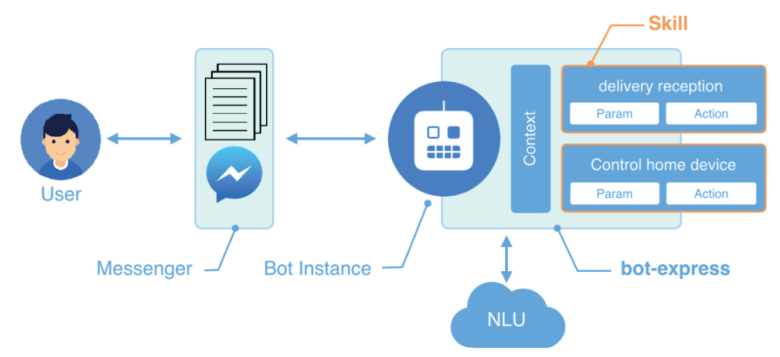

Fig. 2. Natural Language Understanding (NLU)

Digital Personal Assistant is also a software-based service which is designed to help users to complete 
their tasks online. It means understanding voice by the computer and answering questions or managing their schedules, playing music... Acoustic model is created to take both audio recordings of speech and text transcription. Software with a speech recognition engine is used to transform sounds into words. Language model uses different applications and it has the aim to predict what will be next word in a speech sequence. The whole process is shown in Fig. 3.

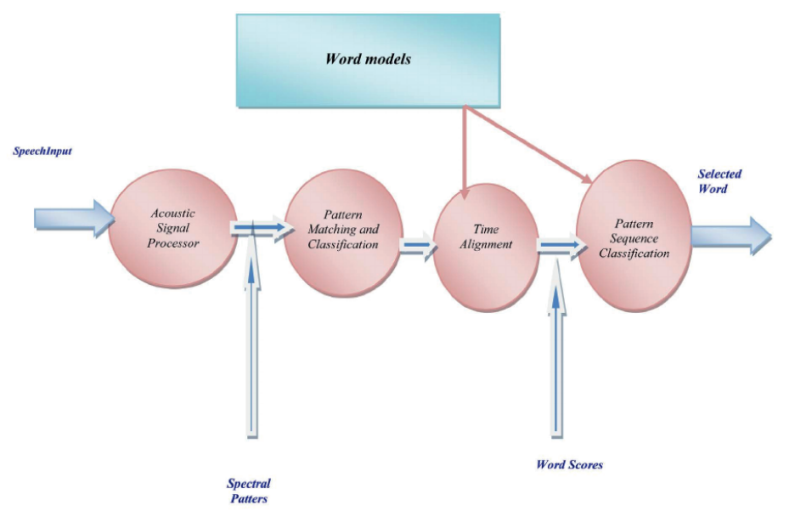

Fig. 3. Diagram of the processing of speech signals planning

Digital personal assistant leaders on the market are: Google Assistant, Siri (Apple), Amazon Alexa, Microsoft's Cortana. [21] When digital assistants have users permission they can collect different data and aggregate them all through search, mail, calendar, maps. They understand who the user is, what are his preferences, where is he, what is he doing, all of this just in order to predict what they really want. For speaker-dependent software new users first speak to the software and it is a kind of training for it because it is important for computer's ability to analyse how the person talks. On the other side, speaker-independent software can recognize anyone's voice, trainings are not necessary. And for better comprehension it is more useful to say simple sentences.

Digital assistants are the best helpers for making brands more popular. This is the best way to build a stronger relationship between brand and its customers. To help brands to become faster, Microsoft has created tools for helping marketers to embed Cortana into their devices and services and also improved Cortana's skills for better extension of their brands. They now have up to 145 million users per month. [22]

\section{CONCLUSION}

Applications of AI and ML in marketing have positive effect on customer satisfaction, and on revenue growth, in general. Marketers have better understanding on marketing, and sales qualified leads, have insight into customer preferences, can optimize marketing campaigns, improve the precision of pricing, and forecast the sales in more accurate, and faster way.

Marketing evidently evolved from traditional, via digital into intelligent. New terms such as marketing intelligence and neuromarketing appeared lately. With new versions of artificial neural network algorithms, smart applications in marketing become more personalized and even better reflect customer needs. Besides academic research in this field, the major benefits of AI application in marketing are also discussed in this paper. Google will soon become semantic search engine, IT companies are running in smart application development, (e.g. Siri, Cortana, Alexa), chatbots, robots and all the other AI applications have many advantages in marketing.

\section{REFERENCES}

[1] IDG Communications, P Kushmaro, How AI is reshaping marketing | CIO, https://www.cio.com/ article/3302739/how-ai-is-reshaping-marketing. html, 2018, (27.03.2019)

[2] M. Purdy and P. Daugherty, Why Artificial Intelligence is the Future of Growth, Canada, Accenture, 2016, pp. 3-26.

[3] K. Warwick, Artificial Intelligence: The Basics, 1st Edition, U.K., Routledge, 2011, pp. 3-5.

[4] L. Christina, M. McDowell, E. Forrest, and B. Hoanca, The Impact of Artificial Intelligence and Virtual Personal Assistants on Marketing, Encyclopedia of Information Science and Technology, vol. 8, 4th ed. Toronto, Canada, IGI Global, 2018, pp. 5748-5757.

[5] M. Milosavljević, Veštačka inteligencija, Artificial Intelligence, Univerzitet Singidunum, Beograd, Srbija, 2015, pp. 39-41.

[6] M. Purdy and P. Daugherty, Why Artificial Intelligence is the Future of Growth, Canada, Accenture, 2016, pp. 3-26.

[7] K. L. Siau and Y. Yang, "Impact of Artificial Intelligence, Robotics, and Machine Learning on Sales and Marketing" presented at Twelve Annual Midwest Association for Information System Conference (MWAIS 2017), Springfield, Ilinois, May 1819, 2017. 
[8] A. L. Samuel, Some studies in machine learning using the game of checkers. IBM Journal of Research and Development, 3(3), 1959, pp. 210-229.

[9] S. Rakthin, R. J. Calantone, J. F. Wang, "Managing market intelligence: The comparative role of absorptive capacity and market orientation" Journal of Business Research, 69(12), 2016, pp. 5569-5577. doi:10.1016/j.jbusres.2016.03.064

[10] M. I. Yagci, S. Kuhzady, Z. S. Balik and L. Ozturk, "In Search of Consumer's Black Box: A Bibliometric Analysis of Neuromarketing Research", Journal of Consumer and Consumption Research, Vol. 10, No. 07, 2018, pp. 101-134.

[11] A. M. Choudhury and K. Nur, "A Machine Learning Approach to Identify Potential Customer Based on Purchase Behavior" presented at 2019 International Conference on Robotics, Electrical and Signal Processing Techniques (ICREST), American International University Bangladesh (AIUB), Dhaka, Bangladesh, January 10-12, 2019.

[12] P. Lagree, O. Cappe, B. Cautis and S. Maniu, Algorithms for Online Influencer Marketing. ACM Transactions on Knowledge Discovery from Data (TKDD), ACM, 2019, pp. 1-30.

[13] A. Aluri, B. S. Price and N. H. McIntyre, "Using Machine Learning to Cocreate Value through Dynamic Customer Engagement in a Brand Loyalty Program", Journal of Hospitality \& Tourism Research, 201X, Vol. 20, No. 10, 2018, pp. 1-23.

[14] S. Dimitrieska, A. Stankovska and T. Efremova, "Artificial Intelligence and Marketing", Entrepreneurship, Blagoevgrad, Faculty of Economics, South-west University "Neofit Rilski", 2018, vol. 6, issue 2, 2018, pp. 298-304.

[15] N. Syam and A. Sharma "Waiting for a sales renaissance in the fourth industrial revolution: Machine learning and artificial intelligence in sales research and practice", Industrial Marketing Management, 2018, pp. 135-146. doi:10.1016/j.indmarman.2017.12.019
[16] C. Olson and J. Levy, “Transforming marketing with artificial intelligence", Applied Marketing Analytics, Volume 3 / Number 4, U.K. Henry Stewart Publications, 2018, pp. 291-297

[17] A. S. Al-Sukkar, A. M. M. Abu Hussein and M. M. Abu Jalil, "The Effect of Applying Artificial Intelligence in Shaping Marketing Strategies: Field Study at the Jordanian Industrial Companies”, International Journal of Applied Science and Technology, Jordan, Global Society of Scientific Research and Researchers (GSSRR), 2013. [Online]. Available: https://ijastnet.com/journals/Vol_3_No_4_ April_2013/1.pdf

[18] T. E. Nordlander, "Artificial Intelligence in Business”, M.S. thesis, De Montfort University (DMU), Leicester, U.K., 2001. [Online]. Available: https:// www.researchgate.net/publication/245235667_AI_ Surveying_Artificial_Intelligence_in_Business

[19] G. Stalidisa, D. Karapistolisa and A. Vafeiadisa, "Marketing decision support using Artificial Intelligence and Knowledge Modeling: application to tourist destination management", presented at: International Conference on Strategic Innovative Marketing, IC-SIM 2014, September 1-4, 2014, Madrid, Spain

[20] T. Guarda, M. Santos, F. Pinto, C. Silva and J. Lourenço, "A Conceptual Framework for Marketing Intelligence", International Journal of e-Education, e-Business, e-Management and e-Learning, Vol. 2, No. 6, December 2012, pp. 455-460.

[21] Stone Temple, Digital marketing agency, E. Enge, Rating the Smarts of the Digital Personal Assistants in 2018, https://www.stonetemple.com/digital-personal-assistants-study/, 2018, (25.03.2019)

[22] The Verge, T. Warren (2018) Microsoft and Amazon release preview of Cortana and Alexa integration, https://www.theverge.com/2018/8/15/17691920/ microsoft-amazon-alexa-cortana-integration-preview-features, 2018, (27.03.2019) 